\title{
A case of spontaneous resolution of idiopathic pulmonary hypertension
}

\author{
ALAN FUJII, MARLENE RABINOVITCH, EDWARD C MATTHEWS \\ From the Department of Cardiology of the Children's Hospital Medical Center and the Department of Pediatrics, \\ Harvard Medical School, Boston, Massachusetts, USA
}

SUMMARY We describe serial electrocardiographic, radiological, and haemodynamic assessment of a young man with spontaneous resolution of idiopathic pulmonary hypertension which was coincident with puberty.

Idiopathic pulmonary hypertension is almost always a fatal disease with an average life expectancy after the onset of symptoms of three years in adults ${ }^{1}$ and one year in children. ${ }^{2} \mathrm{~A}$ few patients, however, live much longer, ${ }^{3-6}$ the longest survivals being in two patients who were still alive 27 and 38 years after the onset of their disease. ${ }^{6}$ We know of only two published case reports, however, in which even partial regression of idiopathic pulmonary hypertension was documented. One describes a 32-year-old woman in whom the pulmonary artery pressure was initially two-thirds systemic level but decreased to less than one-half systemic level after 18 months of anticoagulant treatment. ${ }^{7}$ Another describes an 11 -year-old girl in whom idiopathic pulmonary hypertension regressed after it had reached an advanced stage. Pulmonary artery pressure was at systemic level at the age of 11 years and despite anticoagulants there was progressive deterioration in symptoms until the age of 15 . She appeared to improve, however, after a delayed puberty, and by the age of 19 she was asymptomatic with normal exercise tolerance and an only slightly abnormal pulmonary artery pressure of 40 / $14 \mathrm{mmHg}^{8}$

The following is a unique case report in that it describes an 18-year-old man who had idiopathic pulmonary hypertension diagnosed at the age of 12 years and who, on no anticoagulant or vasodilator treatment, showed spontaneous and complete resolution of his disease by electrocardiographic, radiological, and haemodynamic assessment.

^ Present address: Maine Medical Center, Portland, Maine.

Received for publication 14 May 1981

\section{Case Report}

The patient weighed $3629 \mathrm{~g}(8 \mathrm{lb})$ at birth and was delivered normally at term after a pregnancy complicated by bleeding in the first trimester. Growth and development were essentially normal but at the age of 2 years, he developed temporal lobe epilepsy which was controlled with phenytoin and phenobarbitone. At 11 years of age he began to experience mild to moderate exercise intolerance and was therefore referred to Maine Medical Center for cardiac evaluation. Positive cardiac physical findings included a labile heart rhythm which ranged from 47 to 140 beats per minute, fluctuating with only slight changes in position, and a loud single second heart sound. On the electrocardiogram there was sinus rhythm and pronounced right ventricular hypertrophy (Fig. 1A) and on the chest $x$-ray film there was moderate cardiomegaly and a prominent main pulmonary artery. Cardiac catheterisation showed moderate pulmonary hypertension ( $\mathrm{Ppa}=45$ / $15 \mathrm{mmHg}$ ) and a raised pulmonary vascular resistance $\left(\mathrm{Rp}=7 \cdot 7 \mathrm{U} / \mathrm{m}^{2}\right)$. The pulmonary artery pressure did not decrease with either tolazoline infusion $(1 \mathrm{mg} / \mathrm{kg})$ or the administration of 100 per cent oxygen (see Table). A xenon ventilation perfusion lung scan was also performed and was normal. Four months later the patient underwent repeat cardiac catheterisation at Children's Hospital Medical Center, Boston, for confirmation of the diagnosis. At that study, the pulmonary artery pressure was $80 / 55 \mathrm{mmHg}$, and pulmonary capillary wedge pressure was normal ( 8 to $9 \mathrm{mmHg}$ ). Bicycle ergometry was performed and exercise tolerance was 25 per cent of predicted in 


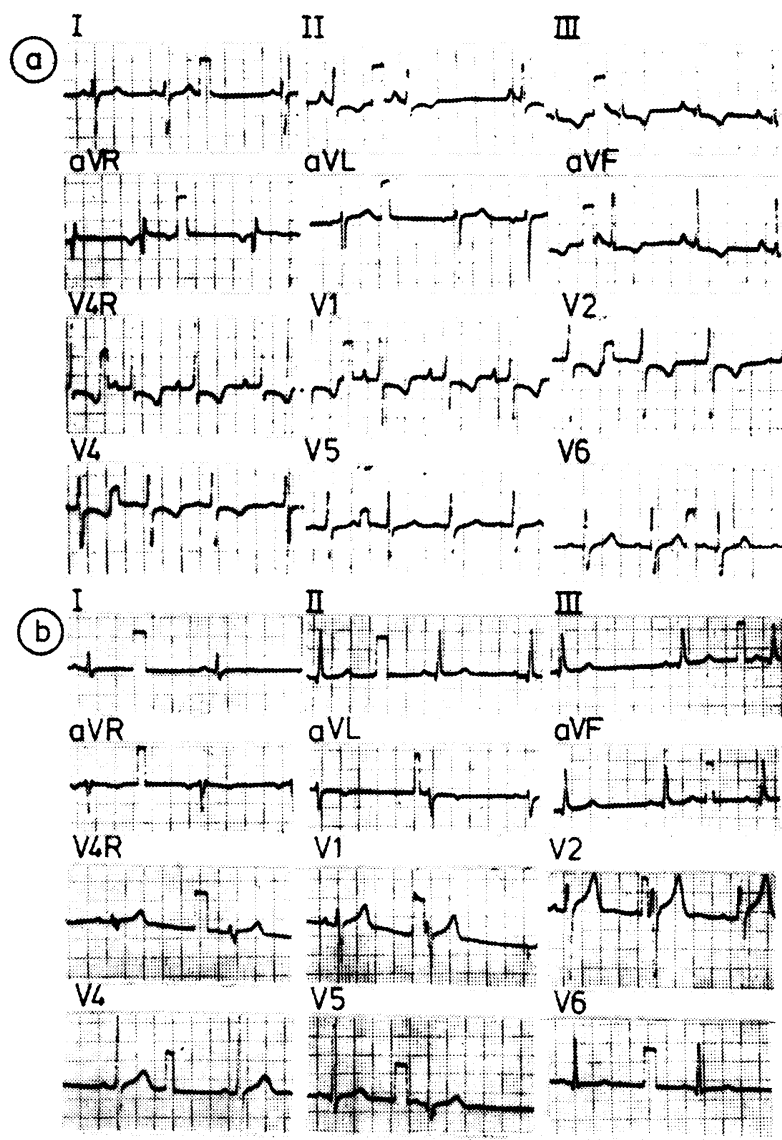

Fig. 1 Electrocardiograms of the patient at the age of 12 years (Fig. 1A) and 18 years (Fig. 1B). At 12 years (13/3/73) right axis deviation ( $Q R S$ axis 120) and right ventricular hypertrophy are present. At 18 years $(19 / 8 / 79)$ the $Q R S$ axis is normal $\left(75^{\circ}\right)$ and no right ventricular hypertrophy is evident.

room air and 50 per cent predicted in 100 per cent oxygen. Exercise at $30 \mathrm{~kg} \mathrm{~m} / \mathrm{min}$ exaggerated the pulmonary hypertension (Table).

The results of other investigations were all normal; these included liver function tests, serum protein analysis, measurements of serum creatinine kinase, an LE cell preparation, antinuclear antibody, and a rheumatoid factor latex fixation test. An electroencephalogram showed posterior slowing with no spike and wave activity and the phenytoin level was in the therapeutic range. He was discharged with the diagnosis of idiopathic pulmonary hypertension.

At home his exercise tolerance gradually improved so that three years later he was even able to participate in moderately vigorous sports. His epilepsy ceased and his anticonvulsants were discontinued. Serial electrocardiograms showed decreasing right ven- tricular forces, and chest $x$-ray films a diminution of his cardiomegaly. A third cardiac catheterisation, performed when the patient was 15 years of age, showed that his pulmonary artery pressure was only $57 / 16 \mathrm{mmHg}$.

At the time of the present study the patient was 18 years old, asymptomatic, and working as a service station attendant. His physical examination, chest $x$-ray, and electrocardiogram were normal (Fig. 1B). An M-mode echocardiogram showed a normal pulmonary ' $a$ ' wave but slightly prolonged right ventricular systolic time intervals (pre-ejection period/ right ventricular ejection time $\left.=0 \cdot 40(\text { normal } 0 \cdot 3)^{9}\right)$. Pulmonary function and exercise tolerance (modified Bruce protocol) were appropriate for his age. A sleep study revealed no nocturnal hypoxia and no epileptiform activity. Cardiac catheterisation showed normal pulmonary artery pressure and pulmonary vascular resistance (Table). Supine exercise on a bicycle ergometer produced a maximum pulmonary artery pressure of only $34 / 14 \mathrm{mmHg}$ with a simultaneous systemic artery pressure of $133 / 89 \mathrm{mmHg}$. Exercise decreased the pulmonary vascular resistance from $2.4 \mathrm{U} / \mathrm{m}^{2}$ at rest to $1.8 \mathrm{U} / \mathrm{m}^{2}$, with a work load of $450 \mathrm{~kg} \mathrm{~m} / \mathrm{min}$. A pulmonary wedge angiogram showed a single small filling defect consistent with an old thromboembolus (Fig. 2)

\section{Discussion}

This is, to our knowledge, only the second published case of documented spontaneous resolution of idiopathic pulmonary hypertension. The pulmonary wedge angiogram provides the only clue to its possible aetiology. In view of his youth, negative lung scan, and absence of thrombophlebitic symptoms, however, it is difficult to be certain that pulmonary thromboemboli were the cause of his pulmonary hypertension. The role of the epilepsy and anticonvulsive therapy is equally uncertain. Though phenytoin has been shown to abolish the pulmonary vasoconstriction in response to acute hypoxia in dogs ${ }^{10}$ there is little evidence to suggest that this drug altered our patient's clinical course. He had been taking it for several years before the onset of his progressive symptoms, continued it during a period of improved exercise tolerance, and despite discontinuing it underwent resolution of his pulmonary hypertension. Since the patient described by Bourdillon and Oakley ${ }^{8}$ also presented at about the same age and became asymptomatic by the age of 19 , it is tempting to speculate about the role of hormones and growth factors in altering the course of this disease.

Previous reports of extended survival and regression of idiopathic pulmonary hypertension 
Table Haemodynamic data at cardiac catheterisation

\begin{tabular}{|c|c|c|c|c|c|c|c|c|c|c|c|c|c|c|c|}
\hline & \multirow[b]{2}{*}{$\begin{array}{l}\text { Age } \\
(y)\end{array}$} & \multirow[b]{2}{*}{$\begin{array}{l}\text { Type of } \\
\text { study }\end{array}$} & \multicolumn{3}{|c|}{$\begin{array}{l}\text { Percentage } \mathrm{O}_{2} \\
\text { Saturation }\end{array}$} & \multirow[b]{2}{*}{$R A$} & \multirow[b]{2}{*}{$\begin{array}{l}P A \\
(\text { mean })\end{array}$} & \multicolumn{2}{|c|}{ Pressure ( $\mathrm{mmHg}$} & \multirow[b]{2}{*}{$S A$} & \multirow[b]{2}{*}{$P C$} & \multicolumn{2}{|c|}{ Indexed flow } & \multicolumn{2}{|c|}{ Resistance } \\
\hline & & & $R A$ & $P A$ & Ao & & & $R V$ & $\begin{array}{l}R V \\
(100 \%)\end{array}$ & & & $Q P$ & $Q S$ & $R P$ & $R S$ \\
\hline \multirow[t]{3}{*}{ (1) } & $121 / 12$ & Rest & 74 & 74 & 98 & 0 & $\frac{42 / 20}{(28)}$ & $44 / 0$ & - & $120 / 70$ & 3 & $3^{\star}$ & - & $7 \cdot 7^{\star}$ & - \\
\hline & & $\begin{array}{l}\text { IV tolazoline } \\
\quad(1 \mathrm{mg} / \mathrm{kg})\end{array}$ & - & - & - & - & $\frac{43 / 17}{(27)}$ & - & - & - & - & - & - & - & - \\
\hline & & Oxygen $100 \%$ & - & - & - & - & $\frac{43 / 20}{(27)}$ & - & - & - & - & - & - & - & - \\
\hline \multirow[t]{5}{*}{ (2) } & $125 / 12$ & & 65 & 65 & 93 & 6 & $\frac{80 / 55}{(60)}$ & - & - & - & 8 & $2 \cdot 6^{\star}$ & - & $20^{\star}$ & - \\
\hline & & $\begin{array}{l}\text { Upright exercise } \\
\text { Rest }\end{array}$ & & - & 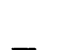 & & & & & & & & & & \\
\hline & & $150 \mathrm{~kg} \mathrm{~m} / \mathrm{min}$ & $\overline{-}$ & $\overline{-}$ & - & - & - & $\begin{array}{l}56 / 0 \\
67 / 0\end{array}$ & $\begin{array}{l}48 / 0 \\
-\end{array}$ & - & - & - & - & - & - \\
\hline & & $300 \mathrm{~kg} \mathrm{~m} / \mathrm{min}$ & - & - & - & - & - & $74 / 0$ & $\overline{74 / 0}$ & - & - & - & - & - & - \\
\hline & & After exercise & - & - & - & - & - & $42 / 0$ & - & - & - & - & - & - & - \\
\hline (3) & $159 / 12$ & Rest & 85 & 85 & 95 & 2 & $\frac{57 / 16}{(29)}$ & - & - & - & - & $4 \cdot 8^{\star}$ & - & $5 \cdot 2^{\star}$ & - \\
\hline \multirow[t]{3}{*}{ (4) } & $1810 / 12$ & Rest & 84 & 84 & 100 & 0 & $\frac{29 / 8}{(15)}$ & - & - & $\frac{112 / 63}{82}$ & 3 & $5 \cdot 1 t$ & - & $2 \cdot 4 t$ & 16 \\
\hline & & $\begin{array}{l}\text { Supine exercise } \\
300 \mathrm{~kg} \mathrm{~m} / \mathrm{min}\end{array}$ & - & 57 & 100 & - & $\frac{32 / 5}{(20)}$ & - & - & $\frac{112 / 82}{94}$ & 3 & $8.3+$ & - & $2 \cdot 0 \dagger$ & - \\
\hline & & $450 \mathrm{~kg} \mathrm{~m} / \mathrm{min}$ & - & 51 & 100 & - & $\frac{34 / 14}{(21)}$ & - & - & $\frac{133 / 89}{106}$ & 3 & $10 \cdot 1 \dagger$ & - & $1.8 t$ & - \\
\hline
\end{tabular}

^ Calculated with assumed $\mathrm{O}_{2}$ consumption.

$\dagger$ Calculated with thermodilution cardiac outputs.

RA, right atrium; PA, pulmonary artery; Ao, aorta; RV, right ventricle; SA, systemic artery; PC, pulmonary wedge; $Q P$, pulmonary blood flow; QS, systemic blood flow; RP, pulmonary resistance; RS, systemic resistance; IV, intravenous.

Fig. 2 Pulmonary wedge angiograms taken with a No. $6 F$ balloon catheter at the origin of the anterior and posterior basal segment pulmonary arteries of the right lower lobe. The pulmonary arteries are normal in size and distribution with gradual peripheral tapering. In one artery (arrow), however, a filling defect is evident and suggests an old pulmonary embolus. 
suggest that there is a wide spectrum of severity. Ours is the second report that indicates that idiopathic pulmonary hypertension in childhood may not be invariably fatal and rarely may resolve spontaneously. Though cardiac catheterisation in these patients is a high risk procedure, ${ }^{11}$ it should be undertaken initially. Later serial study, at least by non-invasive means, is indicated to detect evidence of disease regression as well as to assess the response to various methods of treatment.

\section{References}

1 Wood P. Pulmonary hypertension. In: Diseases of the heart and circulation. 3rd ed. London: Eyre and Spottiswoode, 1968: 976-85.

2 Thilenius OG, Nadas AS, Jockin H. Primary pulmonary vascular obstruction in children. Pediatrics 1965; 36: 75-87.

3 Nielsen NC, Fabricius J. Primary pulmonary hypertension with special reference to prognosis. Acta Med Scand 1961; 170: 731-41.

4 Charters AD, Baker W de C. Primary pulmonary hypertension of unusually long duration. $\mathrm{Br}$ Heart $\mathcal{F}$ 1970; 32: 130-3.
5 Wagenvoort CA, Wagenvoort N. Primary pulmonary hypertension: a pathologic study of the lung vessels in 156 clinically diagnosed cases. Circulation 1970; 42: 1163-84.

6 Suarez LD, Sciandro EE, Llera JJ, Perosio AM. Long-term follow-up in primary pulmonary hypertension. Br Heart $\mathcal{F}$ 1979; 41: 702-8.

7 Wilcken DEL, MacKenzie KM, Goodwin JF. Anticoagulant treatment of obliterative pulmonary hypertension. Lancet 1960; ii: 781-3.

8 Bourdillon PDV, Oakley CM. Regression of primary pulmonary hypertension. $\mathrm{Br}$ Heart $\mathcal{F}$ 1976; 38: 264-70.

9 Williams RG, Tucker CR. Echocardiographic diagnosis of congenital heart disease. Boston: Little Brown, 1977: 59-66.

10 Keane JF, Fyler DC, Nadas AS. Hazards of cardiac catheterization in children with primary pulmonary vascular obstruction. Am Heart $\mathcal{F}$ 1978; 96: 556-8.

11 Mentzer RM Jr, Alegre C, Nolan SP. Effects of diphenylhydantoin (Dilantin) on the pulmonary circulation. Surg Forum 1975; 26: 217-9.

Requests for reprints to Dr Alan Fujii, Cardiology Department, The Children's Hospital Medical Center, 300 Longwood Avenue, Boston, Massachusetts 02115, USA 